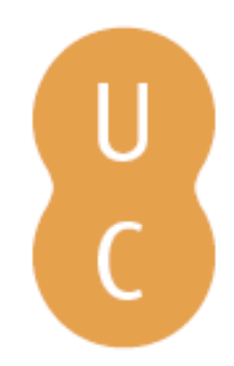

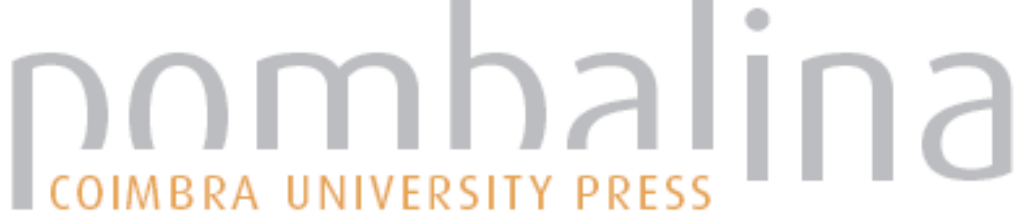

\section{O mundo clássico nas Vidas Apócrifas de Amadeu Lopes Sabino: alguns paralelos imaginados}

\author{
Autor(es): $\quad$ Heuer, Glaucianne Silva dos Santos \\ Publicado por: Associação Portuguesa de Estudos Clássicos; Imprensa da \\ URL \\ persistente: URI:http://hdl.handle.net/10316.2/31839 \\ DOI: $\quad$ DOI:http://dx.doi.org/10.14195/978-972-98142-2-8_19 \\ Accessed : $\quad$ 26-Apr-2023 16:28:46
}

A navegação consulta e descarregamento dos títulos inseridos nas Bibliotecas Digitais UC Digitalis, UC Pombalina e UC Impactum, pressupõem a aceitação plena e sem reservas dos Termos e Condições de Uso destas Bibliotecas Digitais, disponíveis em https://digitalis.uc.pt/pt-pt/termos.

Conforme exposto nos referidos Termos e Condições de Uso, o descarregamento de títulos de acesso restrito requer uma licença válida de autorização devendo o utilizador aceder ao(s) documento(s) a partir de um endereço de IP da instituição detentora da supramencionada licença.

Ao utilizador é apenas permitido o descarregamento para uso pessoal, pelo que o emprego do(s) título(s) descarregado(s) para outro fim, designadamente comercial, carece de autorização do respetivo autor ou editor da obra.

Na medida em que todas as obras da UC Digitalis se encontram protegidas pelo Código do Direito de Autor e Direitos Conexos e demais legislação aplicável, toda a cópia, parcial ou total, deste documento, nos casos em que é legalmente admitida, deverá conter ou fazer-se acompanhar por este aviso.

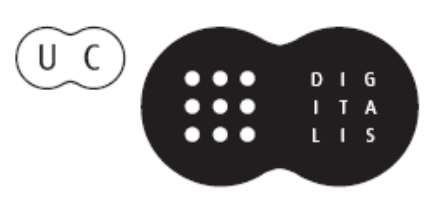




\section{Espaços e Paisagens}

\section{Antiguidade Clássica e Heranças Contemporâneas}

Vol. Il Línguas e Literaturas. Idade Média. Renascimento. Recepção

Francisco de Oliveira, Cláudia Teixeira, Paula Barata Dias (Coords.)

IMPRENSA DA UNIVERSIDADE DE COIMBRA 


\title{
O MUNDO CLÁSSICO NAS VIDAS APÓCRIFAS DE AMADEU LOPES SABINO: ALGUNS PARALELOS IMAGINADOS
}

\author{
Glaucianne Silva dos Santos Heuer \\ Universidade Federal do Paraná
}

\begin{abstract}
The book Vidas Apócrifas, by Amadeu Lopes Sabino, comprises five novels which, in common, describe the tragic destiny of characters who, confronted with the search for a meaning for their multiple lives, are protagonists in more or less fabulous adventures taking place in distant and sometimes exotic countries. In the novels $O$ Silêncio and $A$ Sibila de Badajoz, the scenarios of war set the tone of these adventures, which evokes elements of classical culture to compound them and compare them. Furthermore, in Os tesouros de Alexandre, a kind of postscript, the life of Alexander, whose biography is told in Parallel Lives, by Plutarch (to whom the narrator owes the leitmotif that links the various Vidas Apócrifas), is joining the common lives of the characters of these novels. Therefore, the purpose of this text is to point out some imagined parallels between the classical and contemporary worlds in these first two novels.
\end{abstract}

Keywords: Classical word, contemporary word; Parallel Lives, Vidas Apócrifas.

Palavras-chave: Amadeu Lopes Sabino palavra clássica, palavra contemporanea, Vidas Apócrifas, Vidas paralelas.

O livro Vidas Apócrifas ${ }^{1}$, do escritor português Amadeu Lopes Sabino, reúne cinco novelas que, em comum, descrevem os destinos trágicos de personagens que, confrontadas pela busca de um sentido para as suas vivências múltiplas, são protagonistas de aventuras mais ou menos fabulosas decorrentes em países mais ou menos longínguos, algumas vezes exóticos. Nas novelas "O Silêncio" e a "A Sibila de Badajoz", os cenários de guerra dão a tonalidade dessas aventuras errantes, que evocam elementos da cultura clássica para compôlas e cotejá-las. Em "A Nau Perfeitíssima”, "O Lobo Eterno" e "O Violino", também o mundo moderno das personagens reflete o mundo greco-romano, relacionando-os. Deuses (Zeus, Hermes, Dionísio...), bem como poetas (Virgílio, Homero, Lucrécio...) e personagens da mitologia clássica (Electra, Adamastor, Antígona...) percorrem as páginas dessas novelas contemporâneas. Assim sendo, o objetivo deste texto é o de apontar alguns paralelos imaginados

\footnotetext{
${ }^{1} \mathrm{Em}$ todas as citações referentes ao livro, indicarei entre parentêses apenas a página dessa edição.
} 
entre os mundos clássico e contemporâneo nas duas primeiras novelas do livro, estabelecendo pontes entre ambos os mundos.

$\mathrm{Na}$ novela "O Silêncio", o narrador descreve a trajetória de Ramiro Horta, personagem português que, vivendo a infância e juventude no Portugal salazarista, quando adulto radica-se nos Estados Unidos, passando depois a Israel e Jordânia, por onde segue errante em busca da língua de Babel.

As aventuras de Ramiro são acompanhadas e também experimentadas, de Portugal, pelo amigo de infância e "alter ego", Artur Fernandes. Aliás, a narrativa inicia-se com o anúncio da morte de Ramiro Horta em Aqaba, em telegrama recebido pelo amigo em Portugal:

“(...) Em parte determinada da terra de ninguém entre Israel e a Jordânia, avançara o outro; morto a tiro, em circunstâncias por esclarecer, à beira do Mar Vermelho, nas areias disputadas pelos povos do Livro." (p. 15).

A partir daí, o que se tem é uma retrospectiva da vida de Ramiro Horta numa epopéia moderna dividida em sete capítulos. $O$ caráter audacioso e imprudente de Ramiro é contrastado desde o início com a personalidade prudente e apática do seu amigo Artur Fernandes. Num diálogo entre ambos, tem-se um exemplo:

- Sinto-me - disse Artur - como aquele sábio que, chegado à beira do rio, se senta numa pedra, assistindo, impávido, à tumultuosa passagem das águas.

- Assistir à passagem das águas? - perguntou Ramiro. - Essa sabedoria interessa-me pouco. Eu quero é atravessar o rio, - E, já versado em latim, adiantou um aforismo:- Audaces fortuna juvat! (p. 19)

O aforismo citado por Ramiro remete o leitor à fala de Turno, o anti-herói de Eneida que, no canto X, disposto cegamente a combater Enéas, incita os seus por meio da mesma frase: "Audazes a fortuna favorece" (Virgílio 2005, Canto X, 283). Aqui se tem uma primeira intertextualidade entre "O Silêncio" e a epopéia de Virgílio. Intertextualidade esta que, estendendo-se ao longo da narrativa, estabelece um ponto de contato bastante estreito entre as sagas de Ramiro Horta e do herói troiano.

O herói moderno decidi-se a "partir para Babel" (p. 59), instalando-se, a partir de fevereiro de 1998, em Bersheva, “(...) na orla do deserto do Negueve, onde, entre o estudo do dativo nas línguas semíticas e os amores com uma semita, que conhecera também em Nova Iorque, vai permanecer treze meses" (p. 66-67). E enquanto Ramiro vagava pela região de Aqaba, Artur Fernandes, em Portugal, sofria pela falta de notícias do amigo:

Perdido no deserto - eis a conclusão pessimista do semprepessimista Artur Fernandes. Substituía um colega doente, professor de Latim, e no destino de Eneias inscrevia o de Ramiro:

Musa, mibi causas memora, quo numine laeso, 
Quidve dolens regina deum tot volvere casus

Insignem pietate virum, tot adire labores,

Impulerit. Tantaene animis caelestibus irae!

$<$ Oh, musa!> - lastimava-se Artur, na solidão da Boca do Vento, os olhos marejados de lágrimas, o retrato de Ramiro nas mãos trémulas, <como épossivel que a infelicidade persiga este principe magnânimo, humano e piedoso? > Ia à cozinha preparar mais um uísque, fazendo os possiveis por não despertar Cecilia, que dormia no quarto do casal. A actriz regressara a Almada, à Boca do Vento e ao teatro independente português com a ferida aberta do abandono e da traição, $e$ não queria ouvir pronunciar o nome do ex-amante americano. <Como estão repletas de fel as almas dos deuses e das deusas! > suspirava Artur, contendo os soluços. (p. 71)

Assim como Enéas abandonara Dido para seguir a sua missão determinada pelos deuses, deixando-a furiosa, Ramiro Horta abandonara Cecília nos Estados Unidos para ir em busca do seu tesouro. Isto é, determinado a seguir Samira, a semita que ele conhecera em Nova Iorque. No entanto, deve-se mencionar que, diferentemente do piedoso Enéas, o qual é movido pela obediência ao Fatum e não pela sua própria vontade, Ramiro, destemido e audacioso, é dotado de um caráter hedônico e preza pela liberdade de espírito, cumprindo os seus desejos e as suas ambições como a um dever e exaltando um despojamento que o abre a novas experiências de si.

Além disso, tal qual o herói troiano Enéas, que desce aos infernos, no canto VI da Eneida, acompanhado pela Sibila, personagem mitológica dotada de poderes proféticos, Ramiro Horta, para cumprir a sua saga, acaba também por descer aos infernos. E, ali, o protagonista depara-se com seres míticos que compõem o quadro dos monstros infernais avistados também por Enéas:

Os povos do deserto - admitiu Ramiro - submetem-se de tal maneira aos desígnios da divindade que, fechados do mundo, condenados ao pensamento abstracto pela imensidão do espaço, entendem a sua própria violência como parte integrante da justiça do Senhor. Manteve-se desperto durante horas, deitado num leito de trapos e excrementos de animais, tentando alcançar a razão dos urros dos camelos, adivinhando o dardejar de adagas e punhais, inseguro no meio daquela turba imune à compaixão e à tolerância. Na modorra entre o sono e a vigilia, vislumbrou, no simulacro das formas da noite, a Hidra cujas cabeças sopram ventos de peçonha, a Quimera que lança turbilhóes de fogo, a terrivel Górgona, a ávida Harpia (...) (p. 89)

No entanto, ao contrário do que se passou ao herói troiano, o "herói” dessa epopéia moderna, perdido no meio dos povos do deserto, não consegue tornar atrás e à luz, eternizando-se nas areias da linha militarizada que separa Israel 
da Jordânia. Morto pelo tiro certeiro da arma de Samira, a "donzela-guerreira"2 vestida de homem.

A saga de Ramiro Horta é determinada pelo livre-arbítrio, isto é, sem uma moral familiar, uma crença religiosa e sem mesmo um sentimento de dever para com a pátria. Há apenas o compromisso com a liberdade individual. Desta forma, a saga de Enéas, indivíduo que é nação e que é pátria, ligado a ela numa missão, na qual a vontade subjetiva deve submeter-se a uma lei superior que rege os destinos, contrasta com a do sujeito moderno, o qual empreende uma busca individual e não mais coletiva, numa sede de confronto com os modelos de totalidade. Os fragmentos da Eneida evocados por Ramiro e Artur, refletem, como num espelho invertido, a grandeza e a precariedade, a totalidade e a fragmentação, o apolínico e o dionísico.

O mesmo tema é retomado ao longo das Vidas Apócrifas, Por exemplo, na "A Sibila de Badajoz", que narra a história da vida e morte de Álvaro Carneiro, personagem aventureiro que:

(...) gastou a juventude nas confabulaçôes da I República portuguesa. Estudou Medicina em Coimbra, aproximou-se dos anarquismos politicos e literários, financiou conspiratas e pronunciamentos. Percorreu Europas e Américas e talvez tenha conhecido Lenine em Genebra. Em 1928 publicou no Rio de Janeiro um poema épico que, em dez cantos, celebrava a fraternidade universal. Mais tarde fixou-se em Itália, país onde, entre deuses e sátiros, se sentia em casa. Em 1934, num rompante voltou a Portugal (...) (99-100)

$\mathrm{Na}$ sequência desta narrativa, o relato indireto do narrador dá lugar ao relato direto do padre Joseph Valls, que conhecera Álvaro Carneiro em Nápoles, nos anos 30. O relato feito em 1968 a Mateus Leal, vai esclarecer as lacunas da biografia e as circunstâncias da morte de Álvaro Carneiro. Trata-se de uma tragédia narrada em dois atos que envolve o conflito de Álvaro Carneiro e do próprio padre Valls com os padrões doutrinários da época, apontando para a fragmentação do sujeito, partilhado entre Apolo e Dionísio, na relação entre subjetividade e o Absoluto.

A ilha de Capri, um dos cenários do primeiro ato da tragédia narrada, evoca a mitologia imperial, relacionando-a com o mundo moderno, neste caso, o fascismo de Mussolini:

O professor Torelli fora maçónico na juventude e, embora se tivesse acomodado, colaborando (apenas enquanto arqueólogo, precisava) no restabelecimento da herança romana de que o Duce fizera uma das grandes tarefas da Ditadura, defendia em privado propósitos de tolerância. Teria

${ }^{2}$ A personagem Samira remete para Camila, a guerreira de Eneida. No entanto, o seu disfarce masculino recupera o tema do romance tradicional Donzela que vai à guerra, cujos versos são citados ao longo da narrativa. 
preferido manter-se à margem da recuperação fascista da mitologia imperial (...) (p. 117)

Tal recuperação incluía a residência de Tibério, o segundo imperador romano, sucessor de César Augusto. Imperador de Roma de 14 à 37 d.C., Tibério, afastando-se de Roma, buscou refúgio na ilha de Capri, de onde governou até o fim dos seus dias. De acordo com Suetónio, em Os doze césares, Tibério, na ilha, (...) "Mercê de uma solidão que lhe permitia inteira licença e por assim dizer o escondia dos olhares de Roma, entregou-se, por fim, completamente, a todos os vícios que por muito tempo mal dissimulara (...)" (Suetónio 2007: 184-185).

Em "A Sibila de Badajoz", a relação de Mussolini e seu fascismo com a mitologia imperial, representada aqui pela figura de Tibério, permeia toda a narrativa do padre Valls:

Perdi-me na contemplação dos despenhadeiros marinhos que envolvem a ilha. Tentei imaginar as ninfas e os sátiros de Tibério, entoando cânticos ao prazer è alegria. Mas depressa o crepitar das metralhadoras me ocupou a mente. Não era apenas o Vesúvio que ameaçava explodir. Toda a Europa oscilava entre a sedição e o precipicio. Os aventureiros chegavam ao poder nos partidos e nos Estados, apossavam-se dos arsenais, prometiam o Paraíso. Ora o Paraíso é, há que admiti-lo, a mais perigosa das utopias (...) (p.126)

Assim, "inapto para abraçar ideologias" e, consequentemente, inqualificado "para as práticas colaterais da obediência cega, da adulação e do espírito do corpo" (p.132), o padre Valls, identificando-se com Álvaro Carneiro e a sua liberdade de espírito, vive um conflito com o seu próprio tempo, marcado pelo desejo desmedido do fascismo com "a realização moderna do ideal clássico" (p.133), conforme se observa no relato do seu diálogo com Álvaro Carneiro:

(...) Disse-lhe (...) que a História não é um caminho sem escolbos em direç̧ão à felicidade dos povos, e que o retrocesso civilizacional é possível. Falei-lhe da ideia nietzschiana do equilibrio entre o deus <masculino> do sublime e da tragédia, Apolo, e o deus <feminino> da loucura e da incandescência, Dionísio. Eu queria acreditar no mistério desse equilibrio; a meu ver, o absurdo consistia na predominância de Dionísio, no reino da desmedida, da desrazão e da loucura: no regresso das civilizaçôes às cavernas. (p.134)

Transferindo da Itália para a Espanha, em 1936, na cidade de Badajoz, o padre Valls é encarregado pela Companhia de "organizar a protecção dos arquivos dos jesuítas na Espanha dizimada pela guerra civil" (p.141) e a crueldade da guerra faz com que ele reflita:

(...) Entre o horror e a incomunicabilidade, interrogava-me qual seria o meu papel naquela carnificina: espectador, parte interessada, cúmplice ou autor moral? (...) A guerra promoverame a confiscador de tesouros (...) Uma noite, desanimado, admiti que a Divina Providência 
me desprezava, adestrando na minha pessoa a crueldade dos Antigos e a indiferença dos Modernos. (p. 148)

$\mathrm{E}$ foi assim que, em meio à barbárie da guerra, perseguindo tesouros, o padre reencontrou o seu "alter ego", Álvaro Carneiro, na fronteira entre Portugal e Espanha. E, para reaver um quadro de Zurbarán (1598-1664), de uma figura feminina, "santa, feiticeira ou sibila" (p.150), que Álvaro Carneiro tanto desejara e que agora possuía, o clérigo, cumprindo o seu papel na guerra, dá o tiro que põe termo à vida daquele aventureiro português: "(...) Fechei os olhos e disparei, como a criança que comete o primeiro pecado (...) (p.161)”.

$\mathrm{Na}$ busca destes paralelos imaginados, cabe ainda apontar aqui que, na cultura clássica, a Sibila, dispondo de dons proféticos, era a figura portadora da vontade dos deuses, isto é, do óraculo que dava a conhecer o futuro e o destino das gentes e das terras. Como já mencionado, a Sibila é quem orienta e acompanha Enéas em sua descida aos infernos. Entretanto, a figura da Sibila que tanto Álvaro quanto o padre Valls enxergam no quadro de Zurbarán simboliza o fantasmagórico na busca de um óraculo sibilino no mundo contemporâneo, isto é, simboliza o desejo de uma voz divinatória inaudita.

Desta forma, percebe-se que para além deste entrelaçar o mundo clássico e o mundo moderno, Lopes Sabino apresenta os destinos trágicos de personagens que, desafiando as convenções doutrinárias dos seus Estados e dispondo-se a recusar os cânones estabelecidos, acabam por tornarem-se aventureiros, de acordo com a própria confissão de padre Valls:

Enquanto esperava, fui pensando que o meu desejo de desafiar as convençôes começara por me promover a explorador de tesouros e conseguira, finalmente, fazer de mim um aventureiro. O propósito arrogante de encontrar Deus na recusa dos cânones estabelecidos conduzira-me à beira da perdição. No meio do desalinho das mentes, da

entrega do destino dos homens à violência e à morte, o meu espírito estava prestes a soçobrar na indiferença, que é o pior dos pecados da modernidade. (p. 151)

As viagens são a grande metáfora da existência humana enquanto aventura errática e os embates entre a prudência e a transgressão dos limites, entre "o ascetismo do espírito" e o "júbilo da carne" (p. 135), representam o eterno paradoxo da Humanidade; por isso, como diz o narrador-autor, "os personagens centrais dessas Vidas..., experimentam a capacidade de vivências múltiplas: de preferência apenas duas em simultâneo, porque, como defendia Baudelaire, a coabitação de mais do que duas realidades - ou mais do que duas idéias contraditórias provoca a catástrofe cívica e pessoal, ou, o que é bem pior, a apoplexia poética (...)”(p. 276).

Para finalizar, acrescente-se ainda que, em "Os Tesouros de Alexandre", uma espécie de Posfácio, a vida de Alexandre e a duplicidade da existência do monarca macedônio, cuja biografia é narrada nas Vidas Paralelas, de Plutarco (a quem o narrador deve o fio condutor que cose as várias Vidas Apócrifas), se 
une às vidas das personagens comuns dessas novelas, criando os paralelos. De acordo com Félicien, personagem da novela "O Violino", "Para pintar as paixões dos novos tempos (...) é preciso encontrar novos verbos e novas imagens. Para falar e comover os homens do presente, são necessárias palavras e figuras nunca antes utilizadas (...)"(p. 237). Por sua vez, Amadeu Lopes Sabino, contrariando a sua personagem, busca nas palavras e figuras do mundo clássico, os novos verbos e as novas imagens para pintar as paixões do mundo contemporâneo. Num movimento cíclico que representa o eterno retorno da História, Vidas Apócrifas retoma as questões de identidade, alteridade e transitoriedade, bem como apresenta ao leitor uma reflexão em torno da contradição indissolúvel e trágica da existência humana e em torno das cruéis desmedidas que as ideologias apresentam ontem, hoje e sempre.

\section{Bibliografia}

Amadeu Lopes Sabino (2005), Vidas Apócrifas. Lisboa: Dom Quixote. Suetónio (2007), Os doze Césares. Lisboa: Biblioteca Editores Independentes. Virgílio (2005), Eneida. São Paulo: Ateliê Editorial. 